Keywords: Ufa district of the 17th century, Bashkirs, Kalmyks, Tatars, Mishars, markers of ethnic identity, ethnic interaction, integration, ethnic conflict

СЕЛИВАНОВ Александр Иванович - доктор философских наук, профессор кафедры национальной безопасности Российского государственного университета нефти и газа (национальный исследовательский университет) им. И.М. Губкина (119991, Россия, г. Москва, Ленинский пр-кт, 65, корп. 1; seliv21@mail.ru)

\title{
МЕТОДОЛОГИЧЕСКИЕ ПЛАТФОРМЫ И МЕТОДЫ СТРАТЕГИЧЕСКОГО ПРОГНОЗИРОВАНИЯ: МИРОВОЙ ОПЫТ И РОССИЙСКИЙ ПОТЕНЦИАЛ
}

\begin{abstract}
Аннотация: проводится анализ истории, достигнутых результатов и трендов развития стратегического прогнозирования в США; фиксируется западная методологическая платформа стратегического прогнозирования как синтез позитивизма, прагматизма и субъективного идеализма; обосновывается необходимость сочетания при разработке стратегического прогноза методологических, фундаментальных и прикладных исследований; демонстрируется потенциал материалистической диалектики для разработки отечественной методологической платформы при прогнозах периодических процессов, с учетом духовности социальных образований, путем разработки детерминистических и гармонических моделей, аппликативного метода, учета различий функционирования и развития
\end{abstract}

Ключевые слова: стратегический прогноз, организация, целеполагание, стратегическое управление, методология, метод, позитивизм, прагматизм, субъективный идеализм, материалистическая диалектика

И сследования будущего, его предвидение, прогнозирование наступления/ ненаступления конкретных событий в конкретных объектах, управление будущим - остро актуальная научная проблема и практическая потребность человечества. Несмотря на имеющиеся основания для скепсиса, особенно в связи с сильной неопределенностью [Талеб, 2009], стратегическое прогнозирование все более широко используется в практике управления.

В России предпринимается попытка возрождения государственной системы стратегического управления и отдельные компоненты этой системы включены в нормативную правовую базу (стратегическое планирование, стратегическое прогнозирование, программирование), предпринимаются определенные организационно-управленческие усилия.

Научному сообществу понятно, что система стратегического управления не может существовать без научно обоснованной системы прогнозирования как своего органического компонента. Однако попытки на протяжении десятилетия дать научно обоснованный удаленный прогноз постоянно проваливаются, в том числе в 2017-2019 годах при попытке разработки прогнозов до 2030 и 2035 года. Возникшие серьезные и пока непреодолимые трудности в решении проблем разработки стратегического прогноза привели к тому, что на основе постановления президиума РАН от 27 июня 2018 г. №115 организован Научнокоординационный совет РАН по проблемам прогнозирования и стратегического планирования в Российской Федерации и постановлением президиума 
РАН от 6 марта 2019 г. № 37 утвержден его состав. Он начал проведение постоянного научного семинара, планировавшегося и на 2020 год.

В целом, возникновение серьезных проблем в сфере прогнозирования в России не странно, а закономерно. Уничтожение и последующее 25-летнее игнорирование в практике государственного управления, в науке, в образовании и системе подготовки кадров всего комплекса стратегического управления, включая прогнозирование, не прошли для России даром. В то время как мировая наука и практика в сфере прогнозирования и стратегического управления шли вперед, наша страна «заморозилась» на уровне оперативного ручного управления. Теперь действительно совершенно не просто создать мощную самостоятельную систему прогнозирования, способную соперничать с подобными мировыми структурами. Причем, создать такую систему «по аналогии» одновременно и не представляется возможным, и нецелесообразно, поскольку «по аналогии» можно создать только «догоняющую» систему, что в сфере прогнозирования само по себе бессмысленно - ведь в таком случае достаточно просто идти вслед за «мировыми лидерами». Однако России собственная система социального стратегического прогнозирования совершенно необходима для познания будущего [Романовский, 2015], в том числе для обеспечения стратегического суверенитета. Первым шагом должно стать осмысление методологии и участие в освоении и разработке методов прогнозирования.

\section{Зарубежный опыт}

Открытые и закрытые разработки в сфере прогнозирования ведутся в каждой развитой стране, в крупнейших корпорациях. Более слабые и неразвитые страны и корпорации в отношении государственного стратегического целеполагания и прогнозирования занимают разные позиции: 1) идут в кильватере движения в будущее за передовыми стран, участвуя в общем процессе стратегического целеполагания и прогнозирования в виде международных институтов (как многие страны ЕС, Великобритания, другие союзники США) или просто сознательно следуют в русле их стратегий как выгодной для себя без участия в ее разработке и корректировке; 2) выполняют прямую волю других стран, являясь их колониями; 3) выполняют волю собственных и иностранных корпораций, являясь de facto подчиненными их интересам и целям и также имеющих ослабленный суверенитет и находись в зависимости; 4) не ориентируются на научное обеспечение стратегического целеполагания и прогнозирования вследствие доминирования иного мировоззрения (как, например, арабские страны с мусульманской доктриной построения общества, государства, стратегии развития); 5) не имеют собственной системы стратегического государственного управления и способны лишь на выживание в формате оперативного реагирования на возникающие проблемы (это характерно для малых и слабо развитых стран особенно Африки, Центральной и Южной Америки, Юго-Восточной Азии).

Важно обратить внимание на опыт США, где стратегическое прогнозирование масштабно исследуется и разрабатывается, начиная с 1970-х годов, и его результаты широко применяются в разных сферах. Исследования инициируются и финансируются военными, политиками, бизнесом, разведкой, которые являются и основными потребителями прогнозной продукции. Поэтому часть разработок (неизвестная по объему и эффективности) носит закрытый характер, в том числе прогнозы новых угроз, терактов, видов войн, финансовой динамики и т.д. В профессиональном сообществе известны периодические открытые прогнозные доклады Национального разведсообщества США 
[Глобальные будущие тенденции, 2013; Глобальные тенденции: парадоксы прогресса, 2017; Грибин, 2017; Контуры мирового будущего, 2005; Мир после кризиса, 2011]. Одновременно в США весьма активно велись и ведутся исследования по разработке различных методов углубленного анализа и прогнозирования (известны экспертные методы Дельфи, Форсайта, технологического прогнозирования, качественного анализа PESTEL, SWOT-анализ; STEPанализ; SPACE-анализ и другие), разрабатываются закрытые методы.

Менее известны российскому научному сообществу исследования и разработки в сфере прогнозирования на основе привлечения коллективного разума для решения некоторых (ключевых для американцев) прикладных задач - прогнозы выборов, угроз национальной безопасности, динамики на финансовых рынках. Уместен краткий обзор трех этапов разработки, апробации и применения таких прикладных прогнозов, который подробно описан в серии постов Сергея Карелова ${ }^{1}$ :

- 1968-2003 годы (35 лет): «карта будущего», «рынки прогнозов» по предсказанию будущих событий для обеспечения национальной безопасности (идеолог этого этапа адмирал Джон Пойндекстер);

- 2004-2017 годы: аналитика больших данных (Big Data), краудсорсинг, «трезвый расчет» (прогноз толпы), который исследовался и разрабатывался группой идеолога этого этапа Филипа Тетлока в 1974-2004 годы и привел к созданию весьма эффективных коммерческих прогнозных площадок; IARPA («упреждающая разведка»); аналитика действий для формирования желаемого будущего, разработки и реализации конкретных проектов. Общими целями этого этапа были исследование техники прогнозирования, краудсорсинг, осмысление природы человеческих суждений, выработка принятия решений. Особое внимание обращалось на следующие ключевые аспекты методов и техники прогнозирования: агрегативная условная оценка; наука и техника прогнозирования; краудсорсинг доказательств, аргументации, мышления и оценки; предвидение и понимание из научного изложения; индикаторы с открытым исходным кодом; усиление адаптивного мышления человека для решения проблем; серьезные игры; представление знаний в нейронных системах; комплексная когнитивная архитектура для понимания смыслообразования; машинный интеллект из кортикальных сетей. Коммерческие прогнозные площадки в этот период продемонстрировали высокую эффективность на удалении до одного года.

с 2018 года - эра децентрализованных финансовых систем, децентрализованных баз, сетевых организаций, блокчейна, децентрализованных рынков предсказаний (например, система Augur), более гибких и безопасных, чем аналогичные проекты на предыдущем этапе. На это в настоящее время расходуются большие интеллектуальные и финансовые ресурсы (не менее \$300 млн в год).

Вместе с отсутствием внимания к проблемам прогнозирования из поля зрения российского управленческого и научного сообщества выпала проблема методологии стратегического прогнозирования и его культурных оснований.

Совершенно очевидно то, что и индивидуальный, и коллективный разум (в том числе в прогнозных методиках и технологиях) базируется на конкретной

1 Заключительный пост с интернет-адресами всех предыдущих: Карелов С. «Зима краудсорсинга» заканчивается. ЦРУ проиграло непрофессионалам и это подвигло Facebook заняться коллективным интеллектом // URL: https://medium.com/@ser gey_57776/\%D0\%B7\%D0\%B8\%D0\%BC\%D0\%B0-\%D0\%BA\%D1\%80\%D0\%B0\% D $1 \% 8$ $3 \% \overline{\mathrm{D}} 0 \% \mathrm{~B} 4 \% \mathrm{D} 1 \% 81 \% \mathrm{D} 0 \% \mathrm{BE} \% \mathrm{D} 1 \% 80 \% \mathrm{D} 1 \% 81 \% \mathrm{D} 0 \% \mathrm{~B} 8 \% \mathrm{D} 0 \% \mathrm{BD} \% \mathrm{D} 0 \% \mathrm{~B} 3 \% \mathrm{D} 0 \% \mathrm{~B} 0-$ $\% \mathrm{D} 0 \% \mathrm{~B} 7 \% \mathrm{D} 0 \% \mathrm{~B} 0 \% \mathrm{D} 0 \% \mathrm{BA} \% \mathrm{D} 0 \% \mathrm{~B} 0 \% \mathrm{D} 0 \% \mathrm{BD} \% \mathrm{D} 1 \% 87 \% \mathrm{D} 0 \% \mathrm{~B} 8 \% \mathrm{D} 0 \% \mathrm{~B} 2 \% \mathrm{D} 0 \% \mathrm{~B} 0 \% \mathrm{D} 0$ $\% \mathrm{~B} 5 \% \mathrm{D} 1 \% 82 \% \mathrm{D} 1 \% 81 \% \mathrm{D} 1 \% 8 \mathrm{~F}-\mathrm{dc} 025 \mathrm{~d} 7 \mathrm{bfb} 97$ (дата обращения 30.09.2020) 
культурно-цивилизационной платформе. Соответственно, каждый подход, в отличие от подходов в иных культурах, имеет свои специфические черты, возможности и пределы.

Базовой методологической платформой западной методологии прикладного стратегического прогнозирования является прагматизм и позитивизм, в том числе на основе общего кругозора, информации по проблеме, общего анализа на феноменальном и проявленном причинном уровне, эмпирического опыта, в том числе личного, с дополнением интуиции участников, которая реализует субъективно-идеалистические метафизические конструкции, присущие в особенности англосаксонской культуре. Это позволяет достигать неплохих результатов во многих сферах на относительно небольших горизонтах временного удаления. В коллективном разуме (особенно на коммерческих площадках) к этому дополняются обостренная предприимчивость, чувство конкуренции, инстинкт выживания, постоянное «погружение в проблему» как самые сильные в индивидуализме, исторически отбиравшиеся, широко распространенные и постоянно культивируемые и развиваемые в западной культуре, особенно в США. Более того, современные комплексные аналитические методы, экспертные и коллективные методы позволяют преодолеть многие родовые недостатки позитивизма, базирующегося на фактологическом анализе (и потому в сфере прогнозирования самостоятельно способного производить лишь ретропрогнозы и выстраивать динамические ряды). Однако при этом современными методами лишь компенсируется общая методологическая платформа позитивизма, которая продолжает оставаться базовой.

Важно понимать, что в позитивизме не допускается признание сущности за пределами феноменальной данности (существования), за пределами фактов или по крайней мере - не допускается возможность ее познания. Трансформации позитивизма, включая его постпозитивистские разновидности и вариации постмодернизма, ничего не добавляют к решению главного вопроса - о пределе глубины познания объективной реальности, в особенности духовных сущностей. Поэтому есть несколько обстоятельств, ограничивающих применение данной методологии «в пространстве и во времени». Во-первых, вся данная методологическая платформа и ее практические приложения строго культурно обусловлена и не может быть скопирована и адаптирована в других странах, где просто нет такого количества и качества людей, исторически и культурно-генетических «заряженных» на индивидуалистическое выживание, на постоянное активное и компетентное свойство «держать руку на пульсе» в той или иной сфере, особенно в финансах и политических выборах, и быть на уровне неплохих бытовых экспертов. Во-вторых, такие системы, при всей критике с их стороны, масштабно используют результаты всех научных и аналитических исследований, которые ведутся в самых разных сферах, оценивают и взвешивают их на уровне анализа и интуиции участников прогнозных разработок. И, наконец, в-третьих, на крупном корпоративном и государственном уровнях такие системы непременно модифицируются в подбор и формирование сообществ высококвалифицированных экспертов, деятельность которых теперь дополняется постоянным анализом активности более широких экспертных площадок как дополнительных компонентов коллективного разума. Так, американским разведывательным и научным сообщество для формирования своих прогнозов широко используется метод организации множества тематических конференций по всему миру как одного из основных инструментов разработки удаленных прогнозов. При правильной постановке работы по анализу и оценке получаемой информации это 
дает большие дополнительные прогнозные возможности за счет фактической мобилизации мирового экспертного сообщества. То есть, за счет привлечения множеств экспертов, являющихся носителями других метафизических и мировоззренческих платформ, осуществляется компенсация слабости методологий позитивизма с его феноменальностью и ограниченностью индивидуальным разумом.

В других странах используются различные подходы, недостаточно исследованные российской наукой. По оценкам, весьма продвинутым являются стратегическое прогнозирование и целеполагание в странах с сильным компонентом традиционности (особенно Япония), сочетанием традиционности и марксизма (Китай), социальной ориентацией экономик (ряд европейских стран, особенно скандинавские страны). Всеми странами в сфере стратегического прогнозирования и планирования активно используется разведка и аналитическая разведка.

Вывод: развитые страны активно и масштабно занимаются разработкой стратегических прогнозов в целях государственного и корпоративного управления, используя для этого комплексы институционализированных структур, квалифицированное экспертное сообщество, широкий набор современных научных методов, базируясь на потенциале собственных культур в формировании методологических оснований.

\section{Стратегическое прогнозирование как проблема теории}

Проблемы теории начинаются с самого понятия «стратегическое прогнозирование». Стратегическое прогнозирование - это целеобусловленное прикладное управленческое прогнозирование и компонент системы стратегического управления [Селиванов. Бауэр, 2019]. В системе государственного стратегического управления стратегическое прогнозирование связано с национально-государственной системой целей и целеполагания [Бочаров и др., 2019; Казанцев, 2020; Лепский, 2019; Райзберг, 2016]. Стратегический прогноз диалектически сочетает в себе долгосрочные, дальнесрочные и часть среднесрочных прогнозов в различных сферах, как в узле стягивая их для достижения целей стратегического управления.

При этом стратегическое прогнозирование - не иное название нормативного прогнозирования. Нормативный прогноз, «жестко» задаваемый целью и проектом, во времени обращен от будущего к прошлому, исходит из подчинения настоящего будущему - этот вид прогноза характерен для конкретных проектов. Тогда как стратегический прогноз более практично, многозначно и «мягче» связан с целью и главное - он обращен от настоящего к будущему. При этом он предполагает активное подключение компонентов проектирования и целеполагания при условии, что даже сама цель является (постоянно корректируемым) проектом. Проектирование и создание нового как реализация цели - один из важнейших компонентов стратегического прогнозирования, поскольку это позволяет управлять элементами будущего, делает его во многом активно созидаемым и управляемым, а тем самым более прогнозируемым, снижающим уровень неопределенности будущего. Будущее становится сочетанием неуправляемого и управляемого (проективного), предполагающего органическое взаимодействие прогноза и цели, челночное движение от прогноза к цели и от цели к прогнозу в процедурах прогнозирования и в реализации проектов. Поэтому стратегический прогноз в системе выработки и принятия стратегического управленческого решения - это целостный комплекс, включающий в себя все типы прогнозирования - поисковый, нормативный, аналитический, предостерегающий. 
О методах прогнозирования. Известно, что в прогнозировании применяется обширный и многообразный арсенал научных методов, специальных методик, логических и технических средств. Уже в 80-е годы XX века австрийский футуролог Эрих Янч насчитывал их более 200 и его перечень не являлся исчерпывающим даже тогда, а с тех пор разработано еще множество новых методов. Основные методы прогнозирования (в том числе социального), как известно, сводятся к следующим пяти типам (остальные являются их различными сочетаниями и вариациями): 1) экстраполяция; 2) историческая аналогия; 3) математическое и компьютерное моделирование; 4) сценарии будущего; 5) экспертные оценки. Каждый из них имеет свои достоинства и недостатки.

На сегодня можно утверждать, что формирование качественного прогноза является результатом применения корректно подобранного комплекса методов, целесообразных для конкретного объекта, процесса или ситуации. Это относится и к стратегическому прогнозу, который дополняется специфическими для целеобусловленного прогнозирования методами.

Следующий важный момент. Известно, что точность прогноза, в том числе экстраполяции, убывает по мере продвижения в будущее. «Чем дальше прогноз, тем он приблизительнее» - это методологическое утверждение имеет абсолютно общий характер в своей истинности. Однако здесь необходимо принципиальное уточнение - чем дальше прогноз относительно конкретного объекта (процесса, состояния), тем он приблизительнее количественно, хотя при этом качественные компоненты могут оставаться достаточно точными на существенно большем удалении при сохранении объекта (естественно, в пределах качества исследуемого объекта и его окружения, то есть до перехода объекта в целом в иное качество, требующее иного прогноза). Причем, применительно к развивающимся объектам и процессам развития должен использоваться специальный подход [Селиванов 2015].

Еще один важный момент. Современный опыт развития прикладной прогностики (преимущественно зарубежной) показывает, что стратегическое прогнозирование, несущее ответственность перед системой управления и обществом (корпорацией), требует сочетания фундаментальных и прикладных исследований и экспертных оценок. Так, применительно к обществу фундаментальный анализ обеспечивают социальная философия и конкретные науки - социология, антропология, демография, статистика, политология, психология, культурология, филология и другие, вскрывающие причинные комплексы взаимодействий и систему детерминации процессов различной природы в объектах различной природы. Эти результаты являются (должны являться) базовыми в построении прогнозирования. Применение этих знаний и внедрение в практику - непременный атрибут прикладной междисциплинарной системы стратегического прогнозирования, которые развиваются как самостоятельно значимые, как и экспертное сообщество.

Вывод: эффективный стратегический прогноз это: а) неотъемлемый компонент системы стратегического управления, органически связанный с подсистемой целеполагания; б) результат скоординированной коллективной деятельности и направленных организационных усилий; в) результат сочетания методологических оснований, фундаментальных и прикладных научных исследований и экспертно-аналитических оценок.

\section{Потенциал отечественной методологической платформы в стратегическом прогнозировании}

В советский и постсоветский период российская методология науки (в том числе социально-гуманитарной науки) базируется на традиционном (можно 
сказать натуралистическом) материализме с материалистически же переосмысленными компонентами диалектических и позитивистских разработок. Самостоятельное движение было самоликвидировано характером организации методологических и философских исследований в конце советской эпохи в 70-90-е годы XX века. В социально-гуманитарных науках, в том числе в прогнозировании, был не реализован потенциал теории развития и диалектики. Как итог, фундаментальное конкретно-научное и прикладное (народнохозяйственное, макроэкономическое, статистическое и т.д.) прогнозирование на основе динамических рядов и математических моделей теперь фактически выполняет лишь функции мониторинга и линейной экстраполяции.

Для преодоления этого состояния, к тому же отстающего от мирового уровня, необходимы комплексные усилия. Важнейшим направлением исследований в сфере стратегического управления и прогнозирования являются методологические разработки в отношении познания социального бытия и развития в их диалектической природе.

Потенциал в предвидении и стратегическом прогнозировании российской методологической платформы несравненно выше прагматизма и позитивизма, но необходимы направленные исследовательские усилия по разработке методологии прогнозирования и осуществлении прикладных прогнозов.

Можно выделить следующие принципиальные моменты методологии и перспективных методов российского стратегического прогнозирования:

1. Материализм, базирующийся на признании объективного существования реальности, в отличие от позитивизма, допускает диалектику идеального и материального и предполагает инкорпорирование сущностных духовных компонентов, находящихся за пределами феноменальных фактов, в сферу научных исследований. Это позволяет видеть закономерности за пределами эмпирической реальности, расширяя потенциал научных исследований общества за счет вовлечения в них духовно-культурных и ценностных аспектов социальной динамики. В виде примера приведем лишь феномен консолидации элит и народа для решения выдающихся социальных задач, зафиксированный еще Ибн Хальдуном в понятии «асабия» (согласие) и многократно реализованный в последующей человеческой истории, в том числе в сталинский период в СССР, в Японии и Китае в современную эпоху. То же можно сказать о роли феномена харизмы (М. Вебер) или пассионарности (Л.Н. Гумилев). Это безусловно серьезные детерминанты, которые должны учитываться при расчете прогнозов и колебательных (периодических) процессов в социальных системах.

2. Периодические процессы. Различные частные науки (особенно физика, химия, биология, ряд социальных наук) постоянно углубляют знания о периодических процессах, что особенно важно - они выявляют комплексы причинных связей таких процессов, углубляя базу для объяснения и обоснования экстраполяций с учетом колебательных процессов, определения их границ и тем самым повышая степень научности и достоверности прогнозов. Это безусловно усиливает научные основания исследования периодических процессах. На это уже обратили внимание, особенно российские специалисты (Малков С.Ю., Гринин Л.Е. и другие), хотя некоторые авторы, как это часто бывает с представителями естественных и математических наук, несколько чрезмерно увлекаются абсолютизацией этого феномена в виде формирования течения клиодинамики (Коротаев А.В., Турчин П.В [Турчин 2014; Турчин]). Но если отойти от этой абсолютизации, то исследование комплекса детерминантов крупных трендов и периодических процессов совершенно необходимы и полезны при разработке прогнозов. В частности, речь должна идти об объяс- 
нительных моделях циклов производства К. Маркса, больших циклов (циклов инноваций) Н.Д. Кондратьева - Й. Шумпетера, периодичности смены технологических укладов С.Ю. Глазьева - Д .С. Львова.

3. В западной методологии прогнозирования все более широко используется интуиция экспертов, базирующихся на различных культурных и метафизических конструкциях, и привлекаются специалисты из различных областей (это отражено, например, в «ромбе Форсайта» (И. Майлс, Р. Поппер) [Соколов 2007: 13]). Базовым методологическим основанием этих подходов является субъективный идеализм и мистические учения. Тогда как интуиционизм имеет более глубокие корни в объективном идеализме, рациональной (в том числе материалистической) философии, в русской культуре (доказательство чего могут служить уже работы Н.О. Лосского [Лосский 1995]).

4. Современная материалистическая диалектика, точно оценив диалектичность реального бытия вслед за идеалистическим осмыслением его Платоном, Аристотелем, Г.В. Лейбницем, И. Кантом, Ф.В.Й. Шеллингом, И.Г. Фихте, Г.В.Ф. Гегелем, начала реализовываться в теории К. Маркса и Ф. Энгельса, практической деятельности В.И. Ленина, разработках А.А. Зиновьева, Э.В. Ильенкова, Г.П. Щедровицкого, зарубежных материалистов, но остановился в конце 70-х годов XX века.

Однако даже базируясь на имеющихся разработках, можно уверенно говорить об объективности материальной и идеальной сущности сущего, о природе детерминации и причинном комплексе, о важности анализа единства и борьбы противоположностей во всех случаях развития и реорганизации, о внутренней логике исторических процессов, в том числе процессов развития (диалектической логике) и т.д. Например, необходимо в экономических циклах, в культуре, в больших циклах Кондратьева-Шумпетера, циклах технологических укладов Глазьева-Львова говорить о единстве и борьбе традиции и новации как противоположностях, о старых и новых производительных силах и производственных отношениях. Более того, без такого диалектического углубления исследований невозможно вполне понять природу этих процессов, невозможно осуществлять глубокий стратегический прогноз. Это же можно сказать о соотношении колебаний в популяциях при противостоянии пар хищникжертва в пищевых цепочках, в биогеоценозах (экосистемах) - климат и биота и так далее. Естественно, то же самое можно говорить о колебательных процессах в физике и химии.

Широкий простор для развития стратегического прогнозирования открывается при глубоком анализе, осмыслении и учете диалектической природы онтологических и гносеологических реальностей, развитии на этой основе прикладных методов, в том числе методов использования парных категорий, перечислить которые совершенно не лишне, так как лишь простое вдумывание в контексте стратегического прогнозирования в каждую из пар категорий позволяет понять и оценить их потенциал для стратегического прогнозирования и тем более - активные модельные разработки в осмыслении таких парных категорий, как сущность и явление, содержание и форма, необходимость и случайность, возможность и действительность, порядок и хаос, противоречие и гармония, историческое и логическое, развитие и функционирование, количество и качество, единичное и общее, единство и разнообразие, аналогия и различия, часть и целое (система-элемент), причина и следствие, рациональность и интуиция, объяснение и понимание, истина и ложь, эмпирическое и теоретическое, индукция и дедукция, анализ и синтез, классификация и типология, идеализация и формализация, моделирование, восхождение от конкретного к абстрактному и восхождение от абстрактного к конкретному, 
в человеке - долг и личная свобода, служение и наслаждение и так далее. Эти положения, отражающие сущностные связи бытия, выработаны гигантским трудом человечества, как боевые уставы, которые пишутся кровью. Они сначала стали привычными и банальными для российской мысли, а затем - без прикладных разработок и апробаций - просто выброшены за предел методологии в российской научной мысли, как и в западном позитивизме, перепуганном революциями, который теперь бессильно барахтается без этого колоссального инструментария в осмыслении реальности, в смыслополагании, целеполагании, да и в стратегическом прогнозировании.

5. Гармонические модели и методы в основаниях социального прогнозирования. Они лишь начали зарождаться на основе системных методов анализа соотношения целого и части, научных открытий в синергетике (диссипативные структуры, бифуркации, аттрактор как новое устойчивое (гармоническое) состояние), других вариантов гармонии, в том числе гармонии пространственной организации в виде фракталов. Необходимо также говорить о колебательных и периодических явлениях как гармонических процессах. Все это может и должно дать новый мощный импульс развитию теории и практики прогнозирования.

6. Каузальные, причинно-следственные методы прогнозирования также сушественно более органичны материалистической платформе и обретают в ней комплексный характер. Именно поэтому на данной платформе более понятны и обладают более глубоким объяснительным потенциалом факторные, параметрические и агент-ориентированные модели, возможности использования которых в позитивистском варианте сильно ослаблены.

7. Материалистическая платформа позволяет различить на уровне сущности функционирование и развитие, тем самым создавая устойчивый базис для научной методологии стратегического прогнозирования.

8. Системность (целостность) организации бытия в его материалистической интерпретации позволяет предложить создание многоуровневых аппликативных моделей в качестве образа будущего как цели и как прогноза, которые включали бы в себя разные уровни организации природы и общества и разные удаления достоверного прогнозирования - от биосферного до микросоциального.

ВМЕСТО ЗАКЛЮЧЕНИЯ

Теория и методы стратегического прогнозирования могут получить существенно более глубокое развитие и повысить практическую эффективность стратегического прогнозирования на платформе материалистической диалектики. Это способно усилить возможности человека в стратегическом прогнозировании.

Можно отметить, что стратегическое прогнозирование в настоящее время - активный и эффективный инструмент в наборе инструментов государственного и корпоративного стратегического управления - как в целях обеспечения стратегического суверенитета, так и в обеспечении стратегической коммерческой эффективности. России недопустимо оставаться в стороне от проблематики стратегического прогнозирования - ни по методологическому, ни по культурно-цивилизационному, ни по геополитическому и геоэкономическому потенциалу, ни по стоящим задачам. Необходимо возрождение (создание заново) государственной системы стратегического прогнозирования, включающей в себя фундаментальные, прикладные и экспертные компоненты.

Статья публикуется при поддержке Школы молодого этнополитолога в Республике Башкортостан (грант Фонда президентских грантов 19-2-022447). 


\section{Список литературы}

Бочаров В.Е., Мунтиян В.И., Нехаев С.А. Мировоззренческие и духовнонравственные аспекты стратегического планирования // Разработка системы стратегического планирования и ее интеграция в систему государственного управления: Сборник материалов симпозиума «Проблемы стратегического управления» / Под ред. С.Н. Сильвестрова. М.: Когито-Центр, 2019. С. 129145.

Глобальные будущие тенденции 2030: альтернативные миры. Доклад Национального разведывательного совета США. Декабрь 2012. Краткий обзор. Ташкент, 2013.

Глобальные тенденции: парадоксы прогресса. Доклад национального совета по разведке США. Январь, 2017.

Грибин Н.П. Будущее глазами американской разведки. Аналитический обзор доклада национального разведывательного совета США «Глобальные тенденции: парадоксы прогресса». Аналитические доклады Института международных исследований МГИМО (У). Май 2017. М.: ИМИ МГИМО МИД России.

Казанцев С.В. О стратегическом целеполагании// Страховое дело. 2020. №7 (328). C. 16-24.

Контуры мирового будущего. Доклад Национального разведывательного совета США // Россия и мир в 2020 году. М.: Изд-во «Европа», 2005. С. 7-166.

Леньков Р.В. Социопрогностический подход к социальному управлению высшим образованием России. Дисс. ...д. соц. н. М.: ГУУ. 2016.

Лепский В.Е. Совершенствование стратегического целеполагания на основе системы распределенных ситуационных центров // Разработка системы стратегического планирования и ее интеграция в систему государственного управления: Сборник материалов симпозиума «Проблемы стратегического управления» / Под ред. С.Н. Сильвестрова. М.: Когито-Центр, 2019. С.146-152.

Лосский Н.О. Чувственная, интеллектуальная и мистическая интуиция. М.: Республика, 1995.

Мир после кризиса. Глобальные тенденции-2025: меняющийся мир. Доклад Национального разведывательного совета США. М.: Изд-во «Европа», 2011.

Райзберг Б.А. Целевые программы в системе государственного управления экономикой: монография. 2-е изд. М.: НИЦ ИНФРА-М, 2016.

Романовский Н.В. Будущее как проблема современной социологии//

Социологические исследования (СОЦИС). 2015. №11. С. 13-22.

Селиванов А.И. Познание будущего развивающихся социальных объектов //

Социологические исследования (СОЦИС). 2015. № 4. С.11-17.

Селиванов А.И., Бауэр В.П. О понятии «стратегическое прогнозирование» // Микроэкономика. 2019. № 4. С. 5-15.

Соколов А.В. Форсайт: взгляд в будущее// Форсайт. М., 2007. №1. С. 8-15.

Талеб Н.Н. Черный лебедь. Под знаком непредсказуемости. М.: Изд-во КоЛибри, 2009.

Турчин П.В. Математическое моделирование исторических процессов. Клиодинамика// Теория и методология истории. Учебник для вузов. Отв. редактор: Алексеев В.В., Крадин Н.Н., Коротаев А.В., Гринин Л.Е. Волгоград: Издательство «Учитель», 2014. (Глава 23. С. 447-459)

Турчин П.В. Клиодинамика: новая теоретическая и математическая история // Киберленинка // URL: https://cyberleninka.ru/article/n/kliodinamika-novayateoreticheskaya-i-matematicheskaya-istoriya/viewer (дата обращения 30.09.2020) 
SELIVANOV Aleksandr Ivanovich, Dr.Sci. (Philos.), Professor of the Chair of National Security, National University of Oil and Gas «Gubkin University» (bld. 1, 65 Leninsky Ave, Moscow, Russia, 119991; seliv21@mail.ru)

\title{
METHODOLOGICAL PLATFORMS AND METHODS OF STRATEGIC FORECASTING: WORLD EXPERIENCE AND RUSSIAN POTENTIAL
}

\begin{abstract}
The author States the absence of a strategic forecasting system in Russia and the possibility of developing scientifically based state strategic forecasts; analyzes the state of countries by the nature of the development and use of strategic forecasting; the analysis of the history, achievements and development trends strategic forecasting abroad, especially in the US, which especially applies to the development of methods for strategic forecasting, including expert methods and methods of collective intelligence; assessed Western methodological platform for strategic forecasting as a synthesis of positivism, pragmatism and subjective idealism; the article demonstrates the specifics of strategic forecasting as a goal-based forecasting included in the strategic management system, which determines the specifics of strategic forecasting in relation to other types of forecasting, the combination of long-term and medium-term forecasting, as well as search, regulatory, analytical and cautionary forecasting; the author substantiates the need to combine methodological, fundamental and applied research in research in the field of strategic forecasting and development of strategic forecasts. the author raises the problem of developing a domestic methodological platform based on materialistic dialectics, demonstrates its potential in the study of periodic processes, taking into account the spirituality of social formations, by developing deterministic and harmonic models, an applicative method, and taking into account differences in functioning and development
\end{abstract}

Keywords: strategic forecast, organization, goal setting, strategic management, methodology, method, positivism, pragmatism, subjective idealism, materialistic dialectic 